\title{
Relationship between Detector Size and the Need for Extra Images and their Effect on Radiation Exposure in Digital Mammography Screening
}

\section{Zusammenhang zwischen der Detektorgröße und der Notwendigkeit von Zusatzaufnahmen sowie deren Auswirkung auf die Strahlenexposition im digitalen Mammografie-Screening}

Authors

Affiliations
K. Entz ${ }^{1}$, A. Sommer ${ }^{1}$, W. Heindel ${ }^{1,2}$, H. Lenzen ${ }^{2}$

University Hospital Muenster, Reference Center for Mammography Muenster, Germany, Muenster

2 University Hospital Muenster, Department of Clinical Radiology, Germany, Muenster

\section{Key words}

- detector size

- mammography screening

- digital mammography

- average glandular dose

- photon counting received $\quad 17.10 .2013$

accepted $\quad 10.12 .2013$

\section{Bibliography}

DOI http://dx.doi.org/

10.1055/s-0033-1356429

Published online: 21.2.2014

Fortschr Röntgenstr 2014; 186 : 868-875 @ Georg Thieme

Verlag KG Stuttgart · New York . ISSN 1438-9029

\section{Correspondence \\ Kathrin Entz}

Institut für Klinische Radiologie, Referenzzentrum

Mammographie

Universitätsklinikum Münster

Albert-Schweitzer-Campus 1

48149 Münster

Tel.: ++ 49/2 51/8344130

Fax: ++49/2 51/8345659

entz@referenzzentrum-ms.de

\section{Abstract}

Purpose: To determine the number of extra images (EI) that are necessary for imaging large breasts when using a detector smaller than $24 \mathrm{~cm} \times 30 \mathrm{~cm}$ and to calculate the additional average glandular dose (AGD) for these images.

Materials and Methods: The screening mammograms taken between 2007 and 2011 were assessed for a photon counting full-field digital mammography (PCM) system (detector size: $24 \mathrm{~cm} \times 26 \mathrm{~cm}$ ) and a computed radiography (CR) system $(24 \mathrm{~cm} \times 30 \mathrm{~cm})$. The number of EI was recorded and the AGD calculated. This AGD was compared with the mean AGD of 47 conventional full-field digital mammography (FFDM) systems.

Results: A total of 62,466 examinations were analyzed. EI had to be taken in 0.6\% (199/ 32,766 ) of all PCM examinations and $0.3 \%$ (90/29700) of all CR examinations. This corresponded to a total of 327 and $191 \mathrm{EI}$ for the PCM and CR systems, respectively. More than one quarter of the examinations with EI were necessary because the breast was not properly positioned in the original image (PCM 31\%, CR 29\%). The mean AGD per EI was $0.7 \pm 0.1 \mathrm{mGy}$ for the PCM and $2.6 \pm 1.2 \mathrm{mGy}$ for the CR system. The mean AGD for all breast thicknesses for FFDM was $1.4 \pm 0.3 \mathrm{mGy}$.

Conclusion: In general, large breasts cannot be imaged with just one image per view. The number of examinations where EI are needed is doubled with the $24 \mathrm{~cm} \times 26 \mathrm{~cm}$ detector of the PCM system. However, the absolute number is small. The total dose, as the sum of the original and the EI, is equal to the mean AGD of a single image of the FFDM systems and lower than the dose of a single image with the CR system.
Key Points:

- When imaging large breasts, extra images are also needed on standard detectors.

- The rate of examinations with extra images is doubled with a $24 \mathrm{~cm} \times 26 \mathrm{~cm}$ format of a photon counting mammography (PCM) system.

- The absolute number of extra images required due to detector size is small.

- The total dose (sum of original and extra image) of PCM is below dose limits.

Citation Format:

- Entz K, Sommer A, Heindel W et al. Relationship between Detector Size and the Need for Extra Images and their Effect on Radiation Exposure in Digital Mammography Screening. Fortschr Röntgenstr 2014; 186: 868-875

\section{Zusammenfassung}

Ziel: Für das Mammografie-Screening ist vorgeschrieben, dass die Mamma in der gewählten Projektion mit nur einer Aufnahme adäquat abgebildet werden muss. In dieser Studie wurde untersucht, wie häufig bei Detektoren kleiner $24 \mathrm{~cm} \times 30 \mathrm{~cm}$ Zusatzaufnahmen (ZA) notwendig werden und wie hoch die Strahlenexposition durch diese ZA ist.

Material und Methoden: Für den Zeitraum 2007 2011 wurde ermittelt, wie viele ZA aufgrund einer nicht vollständig abgebildeten Brust an einem Photon-Counting-Scan-DR-System (PC-DR) mit einer Detektorgröße von $24 \mathrm{~cm} \times 26 \mathrm{~cm}$ im Vergleich zu einem Detektor von $24 \mathrm{~cm} \times 30 \mathrm{~cm}$ (CRSystem) nötig waren und die zusätzliche Parenchymdosis (AGD) für diese Aufnahmen berechnet. Zum Vergleich wurde die mittlere AGD für 47 konventionelle DR-Systeme bestimmt.

Ergebnisse: Insgesamt wurden 62466 Untersuchungen ausgewertet. An dem PC-DR-System 
wurden bei 0,6\% (199/32 766) aller Untersuchungen 327 ZA angefertigt, an dem CR-System bei 0,3\% (90/29 700) aller Untersuchungen 191 ZA. Mehr als ein Viertel der Untersuchungen mit ZA (PC-DR $31 \%$; CR 29\%) wurden dabei aufgrund einer nicht optimalen Einstelltechnik in der Primäraufnahme wiederholt. Die mittlere AGD pro ZA betrug an dem PC-DR-System 0,7 $\pm 0,1 \mathrm{mGy}$, an dem CR-System 2,6 $\pm 1,2 \mathrm{mGy}$. Die mittlere AGD über alle Brustdicken der DR-Systeme betrug 1,4 $\pm 0,3 \mathrm{mGy}$.

Schlussfolgerungen: Sehr große Mammae können generell nicht mit einer Aufnahme pro Projektion abgebildet werden. Durch die Verwendung eines Formats von $24 \mathrm{~cm} \times 26 \mathrm{~cm}$ verdoppelt sich die Anzahl der Untersuchungen, bei denen ZA nötig werden, die absolute Anzahl ist jedoch gering. Die Strahlenexposition aus der Summe von Primär- und Zusatzaufnahmen ist bei der PC-DRTechnologie allerdings nur genauso hoch wie im Mittel bei Einzelaufnahmen mit konventionellen DR-Systemen und geringer als am CR-System.

\section{Introduction}

\section{$\nabla$}

It is stipulated in the Federal Covering Agreement between the physicians and the health insurance funds (Bundesmantelvertrag) for the German mammography screening program that the female breast must be able to be adequately imaged in the selected projection with a single X-ray image in every mammography unit [1]. At the same time the XRay Ordinance specifies that any unnecessary radiation exposure as a result of repeat imaging is to be avoided [2]. This is particularly important with respect to ensuring a favorable risk-benefit ratio in a systematic breast cancer early detection program examining symptom-free women. According to the requirements of the Federal Covering Agreement, it is assumed that additional imaging due to a detector size not adapted to the size of the organ can be avoided by the typically used mammography systems with a nominal detector size of $24 \mathrm{~cm} \times 30 \mathrm{~cm}$.

In the case of the photon counting full-field digital mammography system (MDML-30, Sectra Medical Systems, now Philips Healthcare), the detector, in contrast to the otherwise typical nominal detector size of at least $24 \mathrm{~cm} \times 30 \mathrm{~cm}$, has a format of $24 \mathrm{~cm} \times 26 \mathrm{~cm}$. It is known from the literature that this technology has a lower AGD compared with conventional full-field digital mammography (FFDM) and CR systems [3, 4].

The frequency of additional imaging due to inadequate primary parenchyma visualization in the case of the smaller detector of the photon counting full-field digital mammography (PCM) system and the extent of the additional radiation exposure were examined in the present study. The PCM system was compared with a standard CR system of $24 \times 30 \mathrm{~cm}$ with respect to format and for a comparison with respect to dose the average glandular dose (AGD) of conventional FFDM systems was also determined.

\section{Materials and Methods \\ $\nabla$}

The 5-year period from 2007 to 2011 was examined. The scans from two mammography units (unit A and unit B) were evaluated and compared. Mammography unit A (MU-A) used a PCM system (MDM L30, Sectra Medical Systems, now Philips Healthcare) with a nominal detector size of $24 \mathrm{~cm} \times 26 \mathrm{~cm}$, and unit B (MU-B) used a CR system with two Carestream Health imaging plate sizes $(18 \mathrm{~cm} \times 24 \mathrm{~cm}$ and $24 \mathrm{~cm} \times 30 \mathrm{~cm}$ ) on a Siemens Healthcare Mammomat system. The details and technical data of the two systems are provided in $\bullet$ Table 1. The exact field of view (active detector size) of the two compared systems was also determined on the basis of test images. There was an active detector size of $23.8 \mathrm{~cm} \times 26.0 \mathrm{~cm}$ for the PCM detector, while the CR system had an active detector size of $23.2 \mathrm{~cm} \times 29.4 \mathrm{~cm}$. Both analyzed digital imaging techniques thus had a slightly smaller field of view than nominally specified by the manufacturers.

The "MaSc" software used in mammography screening for documentation [5] only allows documentation of "extra images for anatomical reasons". There is no explicit option to document an incompletely imaged breast. Therefore, all "extra images for anatomical reasons" were reexamined in this study and the images on which the female breast could not be fully visualized with one exposure in the primary examination as opposed to extra images that were repeated for other technical reasons (e.g. skin folds) were selected from these images.

The standard examination includes four images: One cranio-caudal (CC) and one medio-lateral-oblique (MLO) image on each side. An examination in which images were acquired in addition to the original images ("extra images") is referred to in the following as an "extended examination". The definitions of the terms are shown in $\bullet$ Table 2.

Extra images were compared with the original images to determine whether the extra images would not have been necessary with a standard size detector and whether the

\begin{tabular}{|lll|}
\hline & mammography unit A & mammography unit B \\
\hline system manufacturer & Sectra Medical Systems & Siemens Healthcare \\
\hline model & MDM L-30 & Mammomat 3000 Nova \\
\hline system type & Scan system (PCM) & Imaging plates (CR) \\
\hline X-ray tube manufacturer & Varian Medical Systems & Siemens Healthcare \\
\hline X-ray tube model & RAD-70B & P40 MoW \\
\hline detector manufacturer & Sectra Medical Systems & Carestream Health \\
\hline detector type & Photon counter & imaging plate (model: EHR-M2) \\
\hline reader model & - & CR 975 \\
\hline nominal detector size & $24 \mathrm{~cm} \times 26 \mathrm{~cm}$ & $18 \mathrm{~cm} \times 24 \mathrm{~cm}$ \\
\hline active detector size (large format) & $23.8 \mathrm{~cm} \times 26.0 \mathrm{~cm}$ & $24 \mathrm{~cm} \times 30 \mathrm{~cm}$ \\
\hline most recent software version & CCS Version 3.8 & $23.2 \mathrm{~cm} \times 29.4 \mathrm{~cm}$ \\
\hline
\end{tabular}

Table 1 Overview of the imaging systems in mammography units $A$ and $\mathrm{B}$. 
breast could have been fully visualized in the original image with better positioning. The part of the breast that could not be visualized in the original image was documented for all extra images.

For the determination and evaluation of the radiation exposure, the average glandular dose (AGD) displayed by the mammography system and the parameters tube load, Xray tube voltage, anode-filter combination, client age, and compression thickness were documented. The AGD could be calculated for mammography unit A on the basis of the exposure settings noted in the DICOM header. However, in the case of the CR system, the exact exposure factors, such as the X-ray tube voltage, the tube load, and the compression thickness, needed to calculate the AGD were not noted in the DICOM header of the images. Therefore, these parameters were taken from the MaSc software. Data records that were incomplete or contained errors were not included in the evaluation.

On the basis of the exposure factors, the AGD was calculated according to Dance $[6,7]$ (equation 1 ).

$\mathrm{D}_{\mathrm{AGD}}=\mathrm{K}_{\mathrm{E}} \cdot \mathrm{g} \cdot \mathrm{c} \cdot \mathrm{S}$

$K_{\mathrm{E}}$ is the incident air kerma in mGy calculated on the basis of the exposure factors and the characteristic curves of the equipment; $g$ is the conversion factor for a standard breast composition with 50\% glandular tissue and 50\% fatty tissue; $\mathrm{c}$ is the conversion factor for deviations from the standard breast composition; and s is the conversion factor for different X-ray spectra. To calculate the conversion factors, an interpolation of the different breast thicknesses was performed [8]. The calculated average glandular doses were then compared with the values displayed by the de-

Table 2 Term definitions.

\begin{tabular}{|c|c|}
\hline term & definition \\
\hline standard examination & $\begin{array}{l}4 \text { images (original images): One CC and one } \\
\text { MLO image each for the left side and for the } \\
\text { right side }\end{array}$ \\
\hline original image & $\begin{array}{l}\text { CC or MLO image acquired during the stand- } \\
\text { ard examination }\end{array}$ \\
\hline extended examination & $\begin{array}{l}\text { standard examination that is supplemented } \\
\text { by additional images (extra images) }\end{array}$ \\
\hline extra image & $\begin{array}{l}\text { an image that is generated in addition to the } \\
\text { original images of the standard examination. } \\
\text { In addition to CC or MLO projections, this can } \\
\text { be a cleavage projection, for example }\end{array}$ \\
\hline
\end{tabular}

vice. The mean compression thickness of the extra images was determined for both mammography units and the particular dose limiting values of the EUREF for these compression thicknesses were determined via interpolation [9]. In addition, the mean AGD and the mean compression thickness for the year 2011 were determined for 47 conventional FFDM systems from the mammography screening program in Nordrhein-Westfalen on the basis of the values documented in the MaSc. Incomplete or incorrect data records were excluded from the calculation. The overall mean value for conventional FFDM systems was calculated from the mean values of all conventional FFDM systems and used for comparison with the average glandular doses of MU-A and MU-B.

\section{Results}

$\nabla$

\section{Analysis of extra images}

In total, 62,466 examinations were performed during the analysis period at the two compared mammography units. In 289 of these examinations ( $0.5 \%$ ), extra images had to be acquired because the breast was not fully visualized. These extra images can be assigned to the two systems as follows: Extra images were required in 199 of 32,766 examinations (0.6\%) using the PCM system. On average, 1.6 extra images were acquired in extended examinations. In total, 327 extra images were generated. It was able to be determined that 107 of the extended examinations $(0.3 \%$ of the total examinations) would not have had to be supplemented by extra images (example in $\bullet$ Fig. 1a) if a standard detector with a field of view of $24 \mathrm{~cm} \times 30 \mathrm{~cm}$ or greater had been used (॰ Fig. 1).

61 of 199 extended examinations (31\%) were performed on the basis of suboptimal positioning in the original images ( $\bullet$ Fig. 2). Approximately two-thirds of the cases with suboptimal positioning (41 cases) related to examinations in which extra images would not have been necessary with a standard detector.

With better positioning, extra images would have been necessary in only 138 cases ( $0.4 \%$ of the total examinations). The number of extended examinations performed due to the smaller detector size would have been reduced from 107 to 66 with optimal positioning. Therefore, the small field of view of the PCM detector would require extra images in $0.2 \%$ of all examinations. The examined breasts were
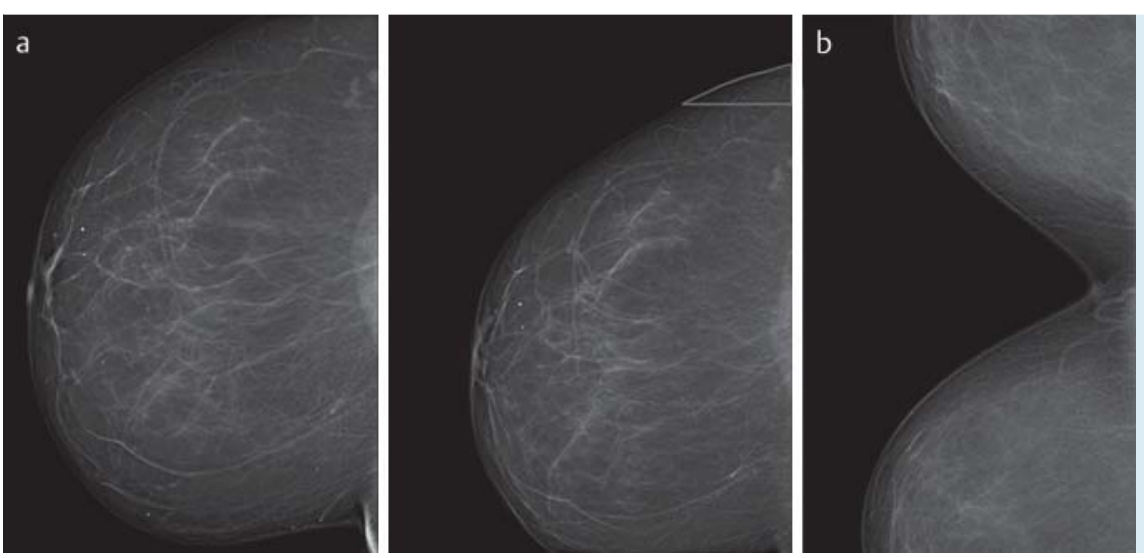

Fig. 1 a Left: Original RCC image of a breast that was incompletely visualized due to the insufficient active detector size of the PCM system. Right: extra image with marking of the approx. 2-cm wide breast section that was not included in the original image. b Example of a cleavage image that should always be considered when the medial portion of both breasts cannot be fully visualized in order to reduce the parenchymal areas with double exposure. 
so large in 72 cases that the field of view of a standard detector would not have been sufficient even with optimal positioning and extra images would still have been necessary. This corresponds to $0.2 \%$ of all examinations of MU-A.

- Fig. 3 shows the percentages of the different projections among the extra images. With $27 \%$ the proportion of LCC images is slightly higher than that of RCC (22\%), RMLO (19\%), and LMLO images (20\%). The percentage of cleavage images ( $\mathbf{~ F i g . ~} \mathbf{1 b}$ ) is $12 \%$.

In the case of the MLO images, the cranial, caudal, and mammillary portions could not be visualized in the original images with approximately the same frequency, while in the case of the CC images, the lateral and medial portions were mainly affected ( $\bullet$ Fig. 4). The mammilla could not be imaged in only two cases on the CC scans.

Extra images were required in 90 of a total of 29,700 mammography examinations $(0.3 \%)$ in the case of the CR sys- tem. In total, 191 extra images were acquired. This corresponds to 2.1 extra images per extended examination.

Extra images would not have been necessary in $29 \%$ of the extended examinations ( 26 cases) if the original positioning had been better ( 0 Fig. 5). 22 of these extended examinations were due to the fact that the breast was positioned suboptimally. The small format $(18 \mathrm{~cm} \times 24 \mathrm{~cm})$ was mistakenly used in 4 extended examinations. Although extra images could not have been completely avoided in 9 extended examinations, the number of extra images could have at least been reduced with better positioning since followup images of both sides were acquired even though only one side was not able to be fully imaged.

After exclusion of the images with incomplete visualization due to suboptimal positioning, extra images were required in 64 examinations due to an insufficient active detector

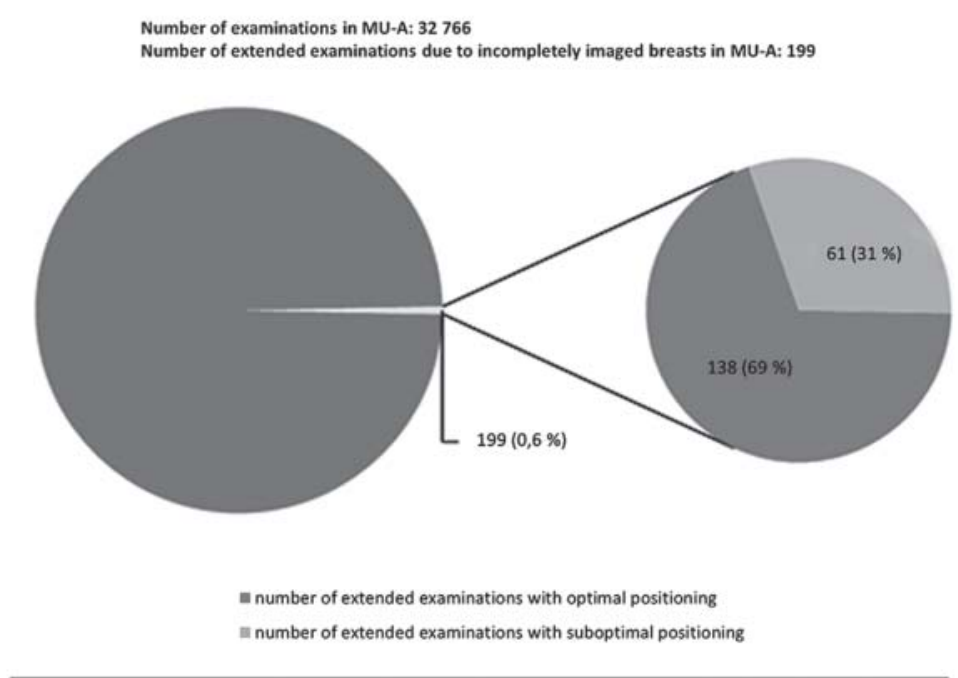

Fig. 2 Extended examinations on the PCM system (MU-A) in the period from 2007 to 2011 categorized according to the quality of the positioning (above) and the quality of the positioning and the detector size (below).

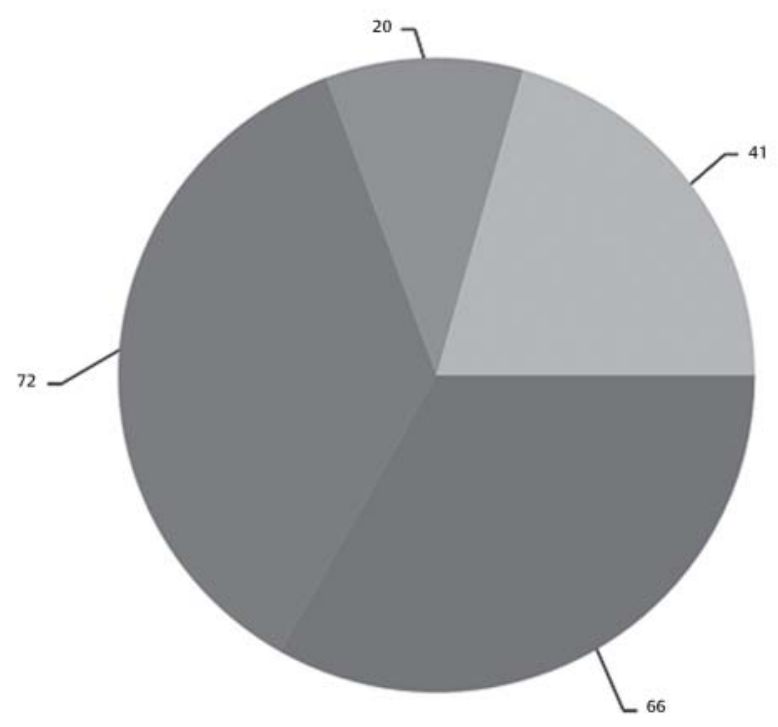

= number of extended examinations due to small detector with optimal positioning number of extended examinations with standard detector and optimal positioning = number of extended examinations with standard detector and suboptimal positioning =number of extended examinations due to small detector and suboptimal positioning 
size. This corresponds to $0.2 \%$ of all examinations performed in MU-B.

The projection had a significant influence on the rate of repetition. The greatest number of extra images was required in the case of the medio-lateral-oblique images ( $\bullet$ Fig. 6 ).

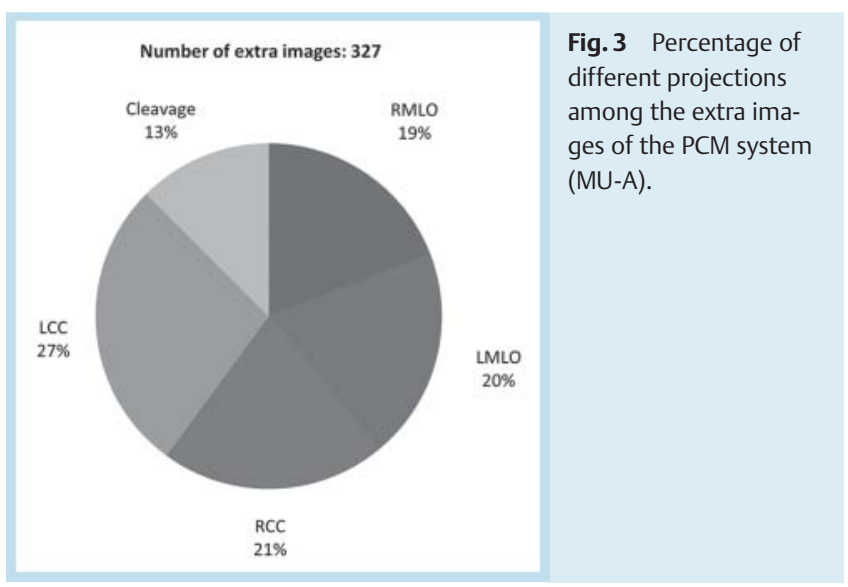

Approximately one-third of the extra images can be allotted to the RMLO images and one-third to the LMLO images. With $2 \%$ the percentage of cleavage images among the extra images is very low.

Part of the breast on the mammilla side was not visualized in $40 \%$ of the incompletely visualized original images ( $\bullet$ Fig. 7). The breast could not be completely imaged on the mammilla side in the MLO images in particular (65 cases). In 9 cases ( $5 \%$ of the extended examinations), more than one extra image in the corresponding projection was required.

\section{Analysis of the additional radiation exposure}

- Fig. 8 shows the radiation exposure due to the extra images for both systems. The calculated dose values and the values displayed by the mammography system are shown. The values specified in the following relate to the calculated mean value of all breast thicknesses used.

The affected women were exposed to an additional AGD of $0.7 \pm 0.1 \mathrm{mGy}$ per extra image or $1.2 \pm 0.7 \mathrm{mGy}$ per examination in the case of the PCM system. The range of the AGD per extra image was $0.3 \mathrm{mGy}$ to $1.1 \mathrm{mGy}$. The calculated AGD

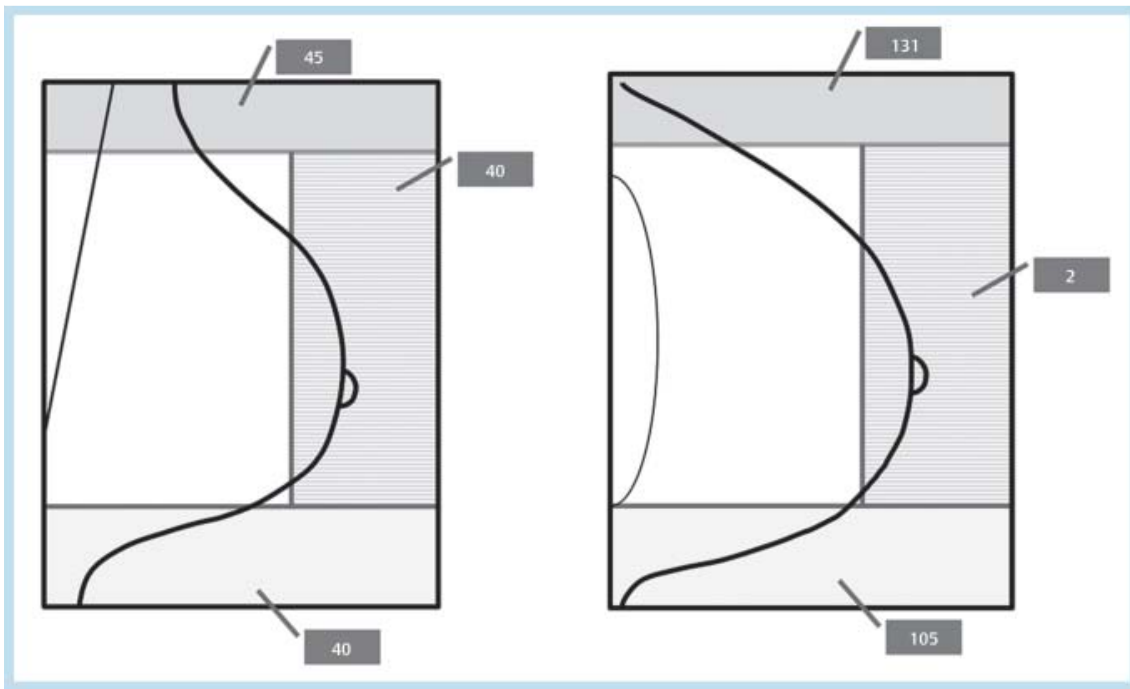

Fig. 4 Schematic representation of the non-visualized parts of the breast in the medio-lateral-oblique (left) and cranio-caudal (right) images on the PCM system (MU-A). The numbers indicate the number of images in which the particular area was not visualized. In some cases more than one part was not visualized.

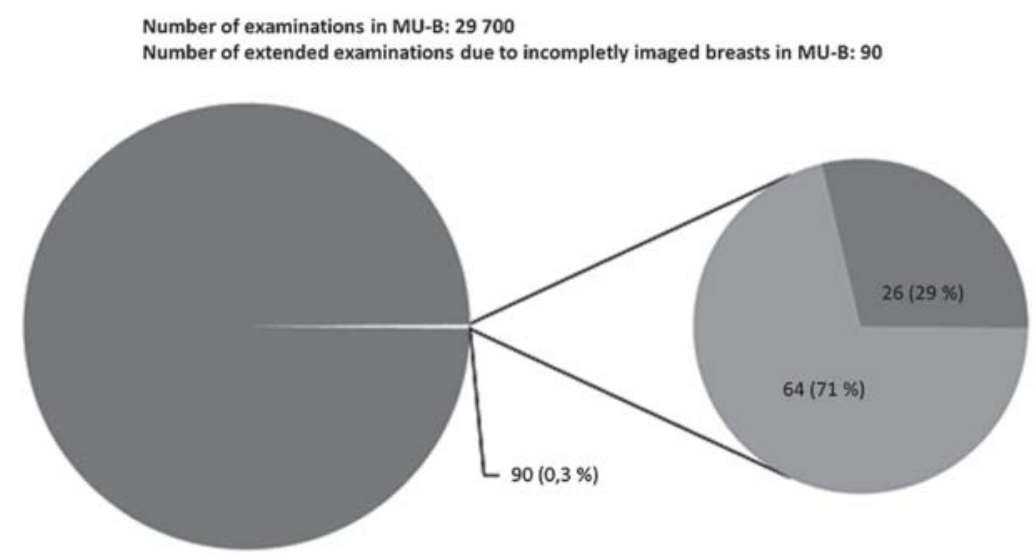

Fig. 5 Extended examinations on the CR system (MU-B) in the period from 2007 to 2011 categorized according to the quality of the positioning. 
values were slightly higher than those displayed by the system (factor $1.2 \pm 0.2$ ). The mean compression thickness for the extra images was $78 \pm 11 \mathrm{~mm}$ (MLO: $83 \pm 12 \mathrm{~mm}$, CC: $75 \pm 9 \mathrm{~mm}$ ) in MU-A. The interpolated EUREF limiting value for this compression thickness is $4.85 \mathrm{mGy}$.

An additional average glandular dose of $2.6 \pm 1.2 \mathrm{mGy}$ per extra image was applied in the case of the CR system. The additional AGD in an extended examination with one or more extra images was $7.0 \pm 3.8 \mathrm{mGy}$. The range of the AGD per extra image was $0.4 \mathrm{mGy}$ to $9.0 \mathrm{mGy}$. The calculated dose values correlated well with the display values of the device documented in the MaSc software (factor 1.0 \pm 0.2 ). The mean compression thickness was $66 \pm 11 \mathrm{~mm}$ (MLO: $69 \pm 10 \mathrm{~mm}, \mathrm{CC}: 58 \pm 10 \mathrm{~mm}$ ) in MU-B. The interpolated EUREF limiting value for this compression thickness was $3.52 \mathrm{mGy}$.

For the year 2011 the AGD of the 47 studied FFDM systems was $1.4 \pm 0.3 \mathrm{mGy}$ per image. The range of the average glandular dose was $0.8 \mathrm{mGy}$ to $2.2 \mathrm{mGy}$ per image. The mean compression thickness of the FFDM systems was $56 \pm 3 \mathrm{~mm}$.

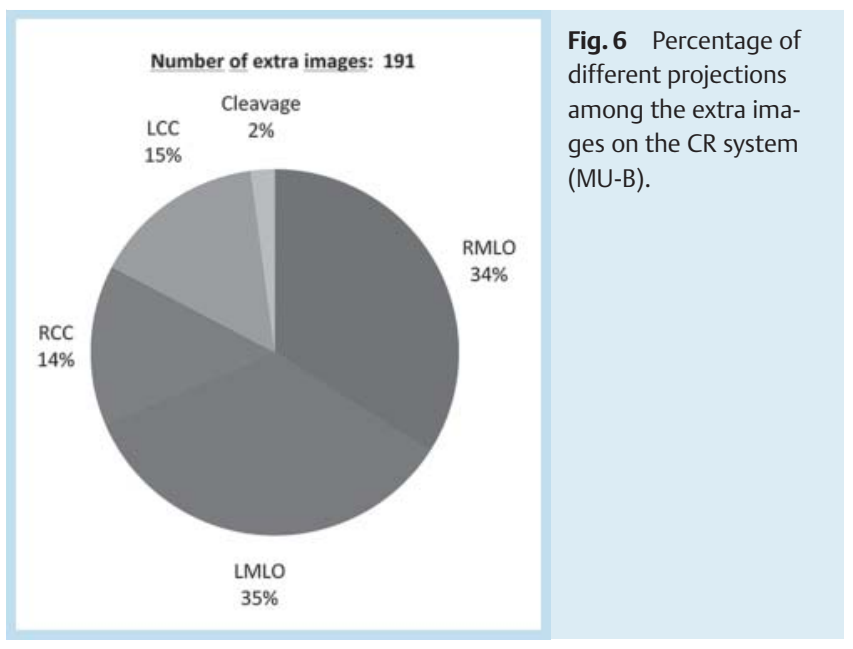

\section{Discussion}

\section{$\nabla$}

In principle, the requirement of the Federal Covering Agreement to visualize the breast with only one image per selected projection cannot be fulfilled even with a $24 \mathrm{~cm} \times 30 \mathrm{~cm}$ detector. This coincides with the results of the screening program in the UK in which the breast was not able to be visualized with one image in the MLO projection in $1.1 \%$ of all participants even though a $24 \mathrm{~cm} \times 30 \mathrm{~cm}$ format was used [10].

Using the PCM detector with field of view of only $24 \mathrm{~cm} \times 26 \mathrm{~cm}$ increases the rate of extended examinations required due to incompletely visualized breasts from $0.3 \%$ to $0.6 \%$. These numbers are significantly below the upper limit of $3 \%$ defined in the Federal Covering Agreement for the percentage of women requiring repeat imaging due to limitations in the diagnostic image quality [1].

Some extra images had to be acquired on the basis of suboptimal positioning for the original images. In mammography unit $A, 31 \%$ of the extended examinations $(0.2 \%$ of all examinations) were the result of suboptimal positioning and this number was $29 \%$ ( $0.1 \%$ of all examinations) in MU-B. Training of radiographers with respect to positioning in the case of large breasts therefore continues to be important and necessary regardless of the detector size in order to lower the number of extended examinations.

After exclusion of the images that were repeated due to suboptimal positioning and the images in MU-A resulting from the small field of view of the PCM detector, $0.2 \%$ of all breasts could not be fully visualized with one image in both units.

The relatively high percentage of cleavage images in MU-A can be explained by the fact that an explicit effort is made in mammography unit $\mathrm{A}$ to perform a cleavage projection instead of the two cranio-caudal projections in extended examinations since the radiation exposure for a cleavage image is usually slightly lower due to the smaller area of overlap than in two separate images for the left and right breast. However, it is not always possible to acquire a cleavage image. The high percentage of cleavage images in MU-A is also the reason that the number of extra images

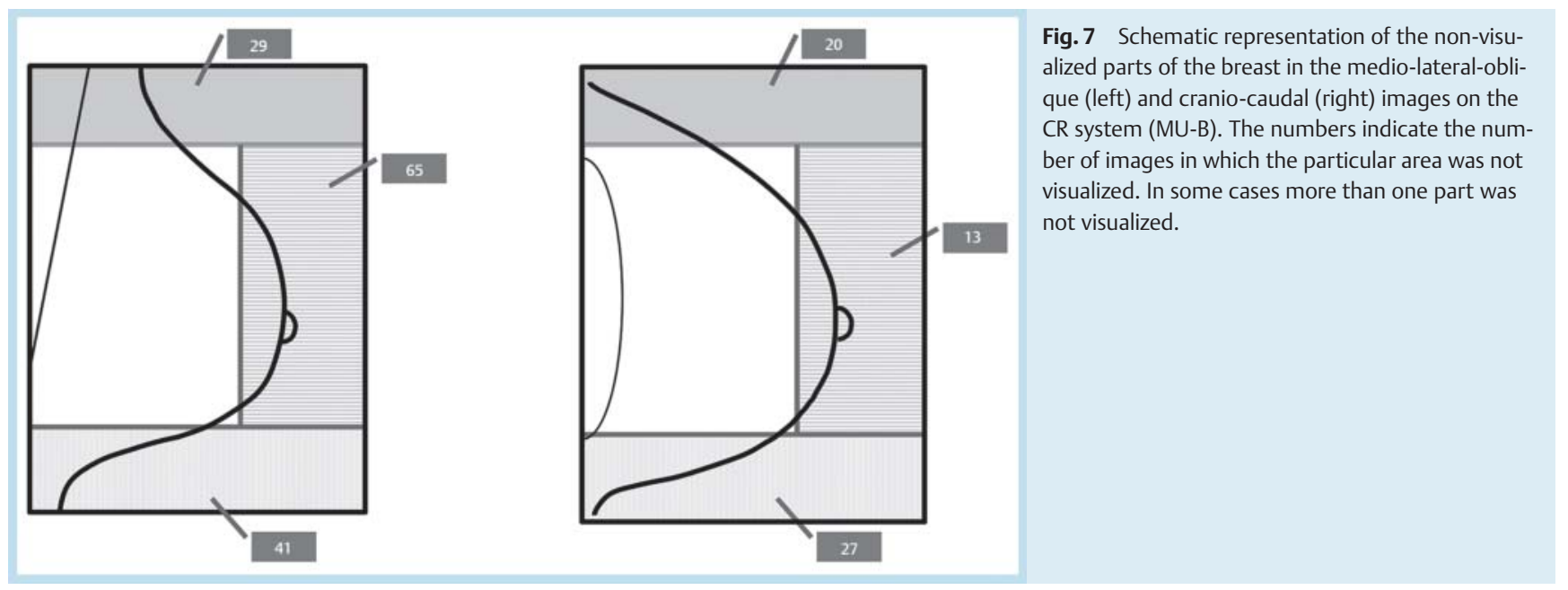




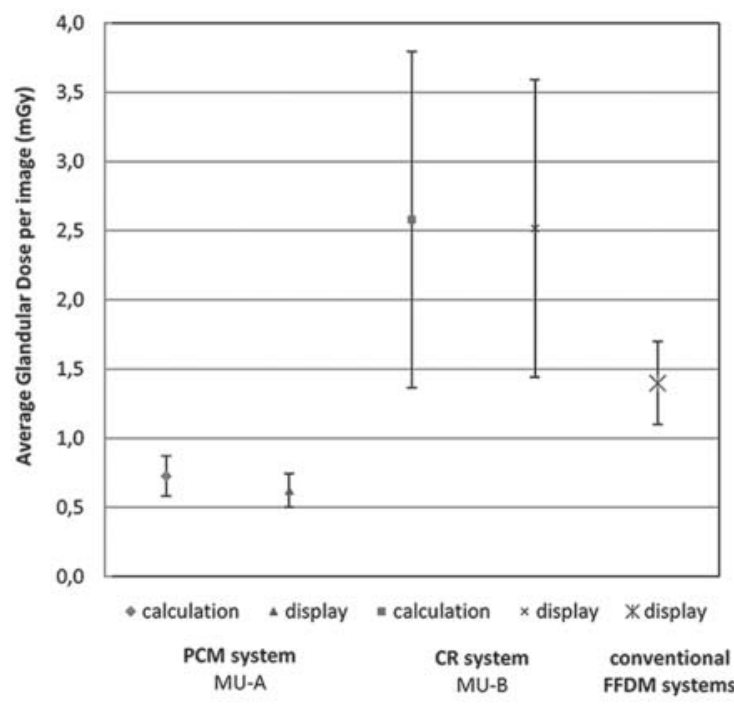

Fig. 8 Comparison of the average glandular dose per image for the PCM system (MU-A), the CR system (MU-B), and conventional FFDM systems. Both the dose values displayed by the device and the values calculated for the PCM system and the CR system are shown. The bars indicate the standard deviation. It must be taken into consideration that the AGD over all breast thicknesses is shown for the FFDM systems but the dose for the extra images with a correspondingly larger breast thickness is shown for the PCM system and the CR system.

per extended examination is significantly lower than in mammography unit B.

The mean compression thickness of the examined images on the CR and PCM system is higher than in the case of both the conventional FFDM systems and the normal collectives in the literature $[11,12]$. A higher compression thickness inevitably results in a higher AGD. For this reason the mean additional AGD of the two examined systems is relatively high compared with other studies $[11,13]$ relating to normally distributed collectives.

47 conventional FFDM systems were used for the comparison of the average glandular dose since the trend in mammography is clearly toward the use of FFDM systems. $84 \%$ of the mammography systems used in the mammography screening program in Nordrhein-Westfalen are FFDM systems and only $16 \%$ are CR systems. As expected, the dose for the CR system was higher than for the PCM system [2]. The higher standard deviation in the dose of the CR system can be explained by the fact that the dose had to be repeatedly increased over the years in order to achieve the necessary image quality [14]. Despite the increase in the dose, the AGD per extra image is still below the EUREF limiting values. The comparison with 47 conventional FFDM systems also used in screening confirms the data from the literature that the average glandular dose of the PCM system is lower [3]. The dose of conventional FFDM systems was determined for all screening participants so that the mean compression thickness is lower than in collectives with large breasts. Nevertheless, the mean AGD of 1.4 mGy per image for conventional FFDM systems is twice as high as in PCM systems.
A limitation of the study is the use of a relatively small collective due to the comparison of only two mammography units resulting in the examination of only two devices. However, an expansion of the study to include additional mammography units and more types of devices would probably not affect the results since the study included a significant number of cases and in general only a few women were affected by the small detector size.

A further possible limitation of the study is that the exposure settings are not stored in the DICOM header in the case of the CR system. Instead, this data is entered in the MaSc software after the examination. Incorrect data records may not have been fully identified and therefore may have been included in the calculations.

In summary, the increase in the rate of repetition caused by the small field of view of the PCM detector seems acceptable due to the overall low number of extended examinations and the equivalent or even lower radiation exposure despite additional exposures.

\section{Summary}

$\nabla$

It is not possible with any of the detectors used in mammography screening to adequately visualize very large breasts with only one image per projection. In these cases extra images are needed to completely visualize the female breast. Therefore, the requirement of the Federal Covering Agreement cannot be fulfilled. The use of the examined PCM system with a detector size of $24 \mathrm{~cm} \times 26 \mathrm{~cm}$ doubles the rate of extra images but at a rate of 107 of 32,766 cases $(0.3 \%)$ is still well below the limiting value of the Federal Covering Agreement (3\%). The total dose (sum of original and extra image) of the PCM system is equal to the mean AGD of a single image of the FFDM systems and lower than the dose of a single image with CR system.

\section{Clinical relevance of the study}

- Extra images are needed to fully visualize very large breasts even when using standard detectors with a size of $24 \mathrm{~cm} \times 30 \mathrm{~cm}$.

- Using a PCM system with a $24 \mathrm{~cm} \times 26 \mathrm{~cm}$ format doubles the rate of examinations with extra images. The absolute number of extra images due to the smaller detector size is nevertheless low $(<1 \%)$.

- The total average glandular dose from the original and extra image corresponds to a single image with a conventional FFDM system and is well below the dose of a single image with a CR system.

\section{References}

1 Kassenärztliche Bundesvereinigung. Vertrag zur Änderung des Bundesmantelvertrags - Ärzte/Ersatzkassen über besondere Versorgungsaufträge im Rahmen des Programms zur Früherkennung von Brustkrebs durch Mammographie-Screening; 2003, Anlage 9.2

2 Verordnung über den Schutz vor Schäden durch Röntgenstrahlen (Röntgenverordnung - RöV) vom 8. Januar 1987 (BGBl. I S. 114), zuletzt geändert am 04. Oktober 2011 (BGBl. I S. 2000)

3 Weigel S, Girnus R, Czwoydzinski J et al. Digital Mammography Screening: Average Glandular Dose and First Performance Parameters. Fortschr Röntgenstr 2007; 179: 892-895 
4 McCullagh JB, Baldelli P, Phelan N. Clinical dose performance of full field digital mammography in a breast screening programme. Brit J Radiol 2011; 84: 1027-1033

5 KV IT GmbH. MaSc Mammographiescreening. Datenerfassung in den Screening-Einheiten. Version 2.0.1-2.7.1.6, 2007-2011

6 Dance DR, Skinner CL, Young KC. Additional factors for the estimation of mean glandular breast dose using the UK mammography dosimetry protocol. Phys Med Biol 2000; 45: 3225 - 3240

7 Dance DR, Young KC, van Engen RE. Further factors for the estimation of mean glandular dose using the United Kingdom, European and IAEA breast dosimetry protocols. Phys Med Biol 2009; 54: 4361 - 4372

8 Sommer A, Lenzen H, Blaser D et al. Prüfanleitung für die Durchführung der ergänzenden Prüfpositionen nach $\mathrm{EPQC} 4^{\text {th }}$ Edition für digitale Mammografie-Systeme - Leitfaden der deutschen Referenzzentren für Mammografie: Version 1.4. Fortschr Röntgenstr 2009; 181: 845 850

9 Perry N, Broeders $M$, de Wolf C et al. European guidelines for quality assurance in breast cancer screening and diagnosis 4th Edition. European Communities; 2006
10 Young KC, Burch A, Oduko JM. Radiation doses received in the UK Breast Screening Programme in 2001 and 2002. Brit J Radiol 2005; 78: 207 218

11 Gosch D, Jendraß S, Scholz $M$ et al. Strahlenexposition bei der digitalen Vollfeldmammographie mit einem Selen-Flachdetektor. Fortschr Röntgenstr 2006; 178: 693-697

12 Olgar T, Kahn T, Gosch D. Average Glandular Dose in Digital Mammography and Breast Tomosynthesis. Fortschr Röntgenstr 2012; 184: 911-918

13 Hermann KP, Obenauer S, Marten K et al. Average glandular dose with amorphous silicon full-field digital mammography - Clinical results. Fortschr Röntgenstr 2002; 174: 696-699

14 Sommer A, Girnus R, Wendt B et al. Entwicklung eines objektiven Bewertungssystems für die jährliche physikalische Qualitätssicherung an digitalen Mammografie-Systemen. Fortschr Röntgenstr 2010; 182: $788-792$ 